\title{
Co-designing with young consumers - Reflections, challenges and benefits
}

\author{
Abstract \\ Purpose: \\ This article explores co-design as a method for actively involving young consumers in the design of an \\ alcohol education program that utilizes an interactive virtual reality (VR) component.

\section{Methodology:} \\ Dietrich et al. (2017) six-step framework was applied to a co-design project involving four groups of \\ 14 to 16-year-old Australian high school students. Data collection included observations by three \\ facilitators, written feedback from members of each group, and video presentations of the generated \\ ideas. The data analysis focused on investigating the applicability of the six-step framework to young \\ consumers, and evaluating the quality and practicality of the generated ideas.
}

\section{Findings:}

Sensitization is key to enabling young consumers to become equal participants during the co-design process. Sensitization allowed the participants to engage in the design task in a playful manner, which fostered active participation and creative insights during the co-design session. A team approach based on interactivity and group autonomy enabled adolescents to contribute insights into their specific needs and wants. This was complemented by a trusting environment, and the presence of immediately available, yet 'hands off' facilitators.

\section{Research limitations/implications:}

The findings are limited to one specific sample and design task. Future research is required that investigates co-design with young consumers in different contexts.

\section{Practical implications:}

The article provides guidance for the application of co-design with young consumers by highlighting the importance of sensitization and facilitation.

\section{Originality/value:}

This study marks one of the first approaches to co-designing alcohol education programs, including VR components, with young consumers. The findings contribute to a better understanding of the consequences of involving young consumers through co-design.

Keywords: Co-design, Service Design, Adolescents, Alcohol Education, Gamification

Paper type: Research paper 


\section{Introduction}

Alcohol is recognized globally as a dangerous substance when consumed in excess, with more than 200 identified health conditions linked to alcohol consumption (WHO, 2014). A particular key challenge for policy makers is to tackle drinking behavior early, that is, to proactively address alcohol consumption among young consumers (Jones et al., 2017, Leontini et al., 2016). One way to do this is through school-based alcohol education programs, which portray the risks of drinking and providing protective strategies for young people when facing drinking situations (Lee et al., 2016). Recent studies point out that the effectiveness of alcohol education is not merely based on knowledge transfer but on student engagement achieved through the integration of interactive and context-specific components that students can identify with (Lee et al., 2016, Onrust et al., 2016). Yet these components are not considered in the current alcohol education programs because these are typically one-way didactic, delivered by teachers to students in a classroom setting (Lee et al., 2016). In addition, the program content is often expert-driven without considering the needs and preferences of adolescents as the target audience of the programs (Thurman, 2015, Dietrich et al., 2016).

Against this backdrop, the present research explores an alternative approach to alcohol education program design and content delivery. Drawing on the emerging field of service design, it is proposed that representatives of the respective target audience can make an important contribution to the content development of new alcohol education programs (Mattelmäki and Visser, 2011). One such a method is co-design, concerned with facilitating close collaboration between experts and end-users throughout the service design process (Steen et al., 2011, Trischler et al., 2017a). However, despite several studies highlighting the potential benefits of co-design (e.g., exploring latent user needs, innovative service ideas), many organizations still lack a clear understanding as to how to involve users as co-designers (Ostrom et al., 2015). This particularly accounts for contexts where targeted users do not perceive themselves as suitable participants (e.g., marginalized groups, vulnerable consumers), or are reluctant to participate (e.g., sensitive topics, lacking identification with the underlying organization) (Engström and Elg, 2015). It is for these reasons that in public services, including areas such as education and health, the design process remains mostly expert-driven with very limited user involvement (Elg et al., 2012).

This study contributes to the ongoing discussion and developments in the service design literature by exploring the involvement of young consumers through co-design. The focus 
thereby is on the active involvement of the targeted user group (i.e., high school students between 14 and 16 years of age) into the content development of a new alcohol education program component that applies gamification. Gamification uses gaming attributes and utilizes them for non-gaming contexts (Deterding et al., 2011, Hamari, 2014). The investigation is underpinned by the following research question:

RQ1: How can young consumers be empowered to actively contribute to the design of new service ideas?

The co-design activities formed part of a large-scale alcohol education program called 'Blurred Minds'. This program offers a range of gamification elements focused on alcohol education that is aimed at young Australian high school students. This includes the integration of a new gamification component, using Virtual Reality (VR) technology, in order to foster student immersion and engagement with the aim to build resilience. Central to its development is the active involvement of representatives of the targeted user group into the early VR content development stages, which focused on ideating peer pressure scenes for a virtual house party.

The findings from this research make a number of important contributions. First, they shed light on how young consumers can be involved through co-design. Little insights are available on the required conditions for empowering young consumers to contribute more actively and directly to the design of new services (Ostrom et al., 2015), particularly in the context of sensitive topics (Dietrich et al., 2017). Second, the study provides insights into the contributions young consumers can make during the ideation stage of the service design process. Scholars have argued that the development of novel and promising ideas is outside the scope of users' normal experiences (Verganti, 2008), and that their involvement might even dilute the quality of the final output (Lehrer et al., 2012). By way of contrast, the present research provides evidence that users can make important contributions to the design process if they are empowered to do so. In particular, the involved users provided insights into the specific language and attitudes of young people today, which enabled the research team to align the context-specificity of the VR content with the respective target market. These adjustments will improve the identification and engagement with the specific activity and the overall program. Finally, with its focus on VR, the study provides insights on how VR and gamification might be used in education programs in general, and alcohol education in particular. Not only are materials delivered in VR seen as entertaining, but the dynamic nature of rich and challenging virtual experiences has been associated with higher order learning and 
knowledge gain beyond mere factual recall (Barko and Sadler, 2012). This is important for allowing those who could be harmed through certain behaviors (e.g., excessive drinking, drug use) to experience the effects of these behaviors in a safe and risk-free manner.

The remainder of this paper is structured as follows. Next, a literature review is presented discussing relevant theory underpinning alcohol education and co-design. The research method is then outlined, followed by the analysis of the data. The article concludes with discussing implications for theory and practice, and providing possible avenues for future research.

\section{Literature}

Alcohol Education - Exploring new approaches

Alcohol education aims to reduce risk factors and enhance protective factors that delay initial use and reduce rates of heavy drinking (Roche et al., 2010, Lee et al., 2016). A range of factors contribute to the uptake and continued consumption of risky drinking behaviors amongst young people, such as the marketing of alcohol messages (Alhabash et al., 2015), and personal factors like low self-esteem, poor self-image and low income (Chaplin et al., 2014). Protective factors on the contrary include better relationships between young people and their parents (Toumbourou et al., 2013), and coping skills (Salom et al., 2016). The WHO reports that younger people (children and adolescents) tend to be more vulnerable to alcohol-related risks factors than adults (WHO, 2014). Adolescents lack the control and agency to counteract positive messages related to alcohol consumption (Baker et al., 2005) and are more prone to peer pressure (Iwamoto and Smiler, 2013). Alcohol education programs take a key role in equipping adolescents with abilities that allow them to become more resilient to for example peer pressure scenarios (Foxcroft and Tsertsvadze, 2011).

Typically, alcohol education programs targeted at young people are conducted in school settings and delivered in a didactic teacher-focused approach (Lee et al., 2016). The program content is expert-driven, that is, evidenced-based and universal messages are applied to a generalized target audience (Dietrich et al., 2015, Newton et al., 2016). Recent studies, however, have indicated that this 'one fits all' approach might not be effective (Lee et al., 2016, Onrust et al., 2016): First, a generalized approach means that young people might not identify with the communicated message, leading to little engagement with or even rejection of the program. Second, the didactic one-way delivery of the content, while often adding to the disengagement of the target audience, additionally requires the teacher to play as the key actor to deliver these types of programs. Yet, teachers might not feel comfortable or have the 
sufficient skills in openly discussing sensitive topics such as alcohol education (Tupper, 2008). These difficulties point towards the necessity to explore new approaches of developing more user-centric alcohol education programs. Co-design, which presents a key concept of service design, might be such an approach as it facilitates the active involvement of those who are affected by design and thus allows outcomes to be streamlined to their specific context and needs.

\section{Co-design as a key concept of service design}

Service design draws on service-dominant logic (S-D Logic), which asserts that value is always contextually specific and uniquely determined by the customer or the beneficiary (Vargo and Lusch, 2008). This means the focus of design is not on value being embedded in services as units of output, but on how value is created in the consumption process through use (Edvardsson et al., 2005). This is because value is not created until the user integrates and applies the resources of the service provider with other resources in their own context (Vargo and Lusch, 2008). Thus, the potential success of a service offering depends on the organization's ability to understand how customers' experience value in their specific context, in order to provide the supporting configuration of resources for customers to integrate and operate on (Patrício et al., 2011).

Service design is "a creative, human-centered and iterative approach to service innovation" (Wetter-Edman et al., 2014). The creative and iterative approach typically includes the following four stages (Patrício and Fisk, 2013): 1) exploration of the user experience within their context; 2) ideation of design concepts relevant to the underlying project; 3) reflection on the concepts, including their prototyping and testing; and 4) implementation of the final design. The human-centered aspect assumes that the key to any design object is to be meaningful to people by supporting them in their actions and experiences (Krippendorff, 2006). This position aligns with S-D Logic and the importance of understanding users' value-creation processes. It is this understanding which makes user involvement through co-design a key concept of service design because it enables consumers, customers, or end-users to contribute unique knowledge about their usage and needs (Gustafsson et al., 2012, Trischler et al., 2017a).

Co-design allows selected users to "become part of the design team as 'experts of their experiences'”' (Sanders and Stappers, 2008). Co-design is a practice that, based on the tradition of participatory design, enables users to contribute their personal wants and needs during the design process (Visser et al., 2005). Holmlid (2009) distinguishes between numerous terms 
that have become commonplace amongst participatory design and service design literature, including the term co-creation. Co-creation is generally considered to be any instance of creativity shared by multiple people during service design (Sanders and Stappers, 2008). In terms of co-creation physical, mental, and/or emotional participation can influence participant interaction in their role as contributors (Prebensen and Xie, 2017, Koc et al., 2017). In contrast, co-design serves a narrower role, referring to the close collaboration between designers and end-users during the service design process (Steen et al., 2011, Trischler et al., 2017a). The aim of co-design is to empower non-designers, representing potential end-users, to incorporate their unique experiences into the design process and contribute innovative ideas (Ind and Coates, 2013, Dietrich et al., 2017). Empowerment in this sense means to construct an environment of autonomy and trust in order to support ideation and innovative dialogue from participants (Hocutt and Stone, 1998).

The present research proposes that alcohol education program design processes should actively involve potential end-users, rather than solely rely on expert knowledge. The benefits of codesign are well documented across many contexts and include reduced risk of new service failure, improved quality and value of the product, and faster development times (Ind and Coates, 2013, Steen et al., 2011, Trischler et al., 2017a). This applies particularly to the early stages of the service design process, which concerns the exploration of the use contexts and overall use experience alongside with the development of new service ideas (Patrício and Fisk, 2013). Based on insights from previous studies, the following section discusses how co-design might be applied to contexts that involve young consumers as the targeted user group.

\section{Co-design with young consumers}

Druin (2002) distinguishes between four roles that young consumers can fulfil during the design process. Ranging from the least to most involved, these are, 1) users, 2) testers, 3) informants, and 4) design partners. Users describe those who use a completed service and their involvement is limited to feedback for future iterations, while testers conduct the same activity but during the prototyping stage of the design process. Both of these roles refer to the back-end of the service design process, which focuses on testing the service prototype rather than incorporating the needs and wants of the target audience directly into the service design (Steen et al., 2011). In contrast, involvement as informants or design partners can refer to all stages of the design process but differ in their form of involvement. While users as informants participate in a passive way, essentially in the role of a respondent speaking only when spoken to, users as a design partner collaborate closely and equally with experts (Witell et al., 2011). Co-design 
refers to the latter form of involvement as it describes each member of the design team, including experts and users, being involved without either member assuming authority of the other (Sanders and Stappers, 2008, Trischler et al., 2017a).

However, the involvement of young consumers as design partners may also be considered the most challenging approach, specifically in terms of planning and facilitating a co-design environment that fosters true collaboration within the team rather than an instruction/obey hierarchy (Vaajakallio, 2009, Van Mechelen et al., 2013). While there are first frameworks available in the literature that provide guidance on how young consumers might be involved through co-design (e.g., Dietrich et al., 2017), these generally do not consider user involvement in design teams. In fact, most studies focus on individual users being involved in innovation activities rather than being part of a design or development team (Trischler et al., 2017b). This is a significant knowledge gap when considering that co-design allows selected users to become part of the design team and collaborate closely with experts during the service design process (Sanders and Stappers, 2008). Consequently, as identified by Ostrom et al. (2015), it remains unclear as to how users can be involved through co-design so that they are empowered to actively contribute their unique knowledge to the ideation of new services. By providing an indepth investigation on the involvement of young consumers in the collaborative development of a new alcohol education program component that utilizes Virtual Reality (VR), the present research goes some way to address this knowledge gap. The study method is presented next.

\section{Methodology}

The present research employs a qualitative method using a real-world context as study setting. This method was deemed appropriate because it provides the researcher with an input of realworld data and recognizes reality as it is, rather than settling for descriptions for the convenience of the researcher and his or her analysis (Perry and Gummesson, 2004). To systematically plan and facilitate the co-design sessions, the research adopted Dietrich et al.'s (2017) six-step framework for involving vulnerable consumers through co-design. Table 1 provides a summary of each of the six steps and outlines how they were applied to this study.

Table 1 - Stepwise application of co-design to the present study.

\begin{tabular}{lll} 
Steps & Description and Aims & Application to present study \\
\hline Resourcing & $\begin{array}{l}\text { Forming a deeper understanding of the problem } \\
\text { to be addressed, including its context and } \\
\text { designerly tools to be used (Dietrich et al., 2017). }\end{array}$ & $\begin{array}{l}\text { A comprehensive literature review investigated the topics of } \\
\text { peer pressure, alcohol education and VR. Script scenes that } \\
\text { contained peer pressure scenarios were resourced from the } \\
\text { full script that was developed for the 'TBA' VR house party } \\
\text { production. }\end{array}$ \\
\hline
\end{tabular}




\begin{tabular}{|c|c|c|}
\hline Planning & $\begin{array}{l}\text { Includes multiple meetings between } \\
\text { developers/session facilitators to decide on a } \\
\text { defined user group, venue, and other operational } \\
\text { issues. Tailor the specific co-design session to } \\
\text { the intended sample (Dietrich et al., 2017; Piper } \\
\text { et al., 2012; Visser et al., 2005). }\end{array}$ & $\begin{array}{l}\text { A team of three researchers with a background in marketing, } \\
\text { gamification and service design collaboratively planned the } \\
\text { subsequent stages of recruitment, sensitization, facilitation } \\
\text { and evaluation. This included the activities and components } \\
\text { of the co-design session, such as the development of a run- } \\
\text { sheet, screening survey, and the group activities. }\end{array}$ \\
\hline Recruitment & $\begin{array}{l}\text { The focus is on recruiting suitable users for the } \\
\text { co-design activity. This often involves the close } \\
\text { collaboration with relevant organizations } \\
\text { (Dietrich et al., 2017; Visser et al., 2005). }\end{array}$ & $\begin{array}{l}\text { Students were recruited via an Australian public secondary } \\
\text { school. The research team collaborated closely with the } \\
\text { school prior to sensitization and the actual co-design activity } \\
\text { to secure a sufficient number of participants. The school also } \\
\text { provided the venue for the co-design session. }\end{array}$ \\
\hline Sensitizing & $\begin{array}{l}\text { Participants are familiarized with the underlying } \\
\text { subject addressed in the co-design session. This } \\
\text { stage also allows for clarification regarding the } \\
\text { purpose of the session, the service being } \\
\text { developed, and the guidelines for the session. } \\
\text { Sensitizing can come in different styles and } \\
\text { consist of multiple stages leading up to the co- } \\
\text { design session (Dietrich et al., 2017; Mattelmaki } \\
\text { and Visser, 2011). }\end{array}$ & $\begin{array}{l}\text { Adolescents tested four newly developed online games for } \\
\text { the 'TBA' program two days prior to the co-design session. } \\
\text { This first sensitizing phase gave adolescents the opportunity } \\
\text { to engage, discuss and reflect on the context and materials of } \\
\text { alcohol education. A second phase directly preceded the co- } \\
\text { design facilitation stage and consisted of a screening survey, } \\
\text { showcasing a simulation experience, and a head-mounted } \\
\text { VR display, and team-specific activities. }\end{array}$ \\
\hline Facilitation & $\begin{array}{l}\text { Includes all activities by the session facilitators } \\
\text { from the end of sensitization through to the } \\
\text { conclusion of the co-design session. The focus is } \\
\text { on guiding, interacting and assisting those who } \\
\text { are typically not part of the design process to } \\
\text { actively co-explore and co-design (Dietrich et al., } \\
\text { 2017; Manzini and Rizzo, 2011). }\end{array}$ & $\begin{array}{l}\text { The facilitation began with a brief introduction of the } \\
\text { research team as well as highlighting the aims of the session. } \\
\text { Four teams were formed by the researchers through a } \\
\text { random allocation procedure. Co-design toolkits were } \\
\text { distributed and consisted of butcher paper, stickers, markers, } \\
\text { coloring pens and post-it notes. The sessions concluded with } \\
\text { a two-minute pitch presentation of each idea to the entire } \\
\text { group. }\end{array}$ \\
\hline Eva & $\begin{array}{l}\text { Focuses on evaluating the generated ideas in } \\
\text { terms of their potential for service design. Also } \\
\text { includes a reflection on the co-design session, its } \\
\text { purpose, and an assessment of facilitators in their } \\
\text { roles. (Donetto et al., 2015). }\end{array}$ & $\begin{array}{l}\text { All data derived from the developed ideas as well as the } \\
\text { presentation transcripts were analyzed using Yin et al.'s } \\
\text { (2011) framework following a five-step process of } \\
\text { compiling, disassembling, reassembling, interpreting and } \\
\text { concluding. The research team reflected on the planning and } \\
\text { facilitation of the co-design session for exploring possible } \\
\text { ways for identifying key aspects that require consideration } \\
\text { when young consumers were involved through co-design. }\end{array}$ \\
\hline
\end{tabular}

\section{Study Setting}

The study formed part of a larger alcohol education program, called 'Blurred Minds'. 'Blurred

Minds' is a comprehensive stratified randomized controlled trial that will be delivered to adolescents and their parents in Australian high schools throughout 2017. It features a suite of gamification activities focused on alcohol education. The program includes a total of five lessons, each focusing on different learning outcomes. Lesson five is focused on strengthening resilience and reducing peer pressure susceptibility, where the notion of peer pressure is highlighted through an innovative VR simulation in the form of a house party. This simulation script aims to showcase the pressures faced by adolescents in party settings to drink alcohol and improve their susceptibility to succumb to peer pressure. The story was filmed using a 360degree video camera and involved numerous actors and extras sourced from a cohort of young adults. Filming of both a male and female version was done in a suburban property in an Australian city over the course of two days. To identify insights of what would produce more 
realistic peer pressure scenes than those used in the first version of the simulation script codesign was applied to redesign the scenes from the script.

\section{Participants}

Purposive sampling was conducted to recruit participants from a public secondary school's tenth grade cohort, which resulted in a sample of 22 participants between 14 and 16 years of age. This sampling approach ensured that the generated insights would reflect the experiences and attitudes of the intended end-user population. From the respective sample, 10 participants were female and 12 were male. The recruited participants were also part of a pre-sensitization activity which was conducted approximately one week prior to the actual co-design session. The co-design session included four groups and three facilitators. During the session, a teacher from the school attended as a supervisor to liaise between the research team and the students. Ethical clearance was acquired as part of the 'Blurred Minds' program. The school and each participant provided consent for the participation in the co-design sessions.

\section{Data collection method}

Data was collected in three ways. First, written feedback was collected from each co-design team. In particular, the co-design teams developed their feedback and new ideas onto large sheets of butcher paper. Feedback focused on three dimensions: 1) what the participants liked about the current script, 2) what they did not like, and 3) specific suggestions on how the script could be improved. Second, the teams finished the co-design session by presenting their ideas by means of a two-minute pitch presentation. This provided students the opportunity to further elaborate on their written notes from the butcher paper. Third, each member of the research team observed and facilitated the co-design session, and filled in a facilitator report immediately after the session. The focus was on reporting specific peculiarities with the individual teams, such as group dynamics, forms of participation by individuals, and the specific approach taken to develop new ideas.

\section{Data analysis}

The data was analyzed by using Yin's (2011) five phase framework, complemented by the CAQDAS (computer assisted qualitative data analysis) method. The analysis focused on two key aspects: First, the six-steps (see Table 1) were reviewed to evaluate their applicability to involving young consumers through co-design. Doing so provides a more nuanced understanding of the specific requirements for involving young consumers through co-design. Second, themes were identified that provide insights on the outcomes generated by the 
participants. This included an in-depth evaluation of the generated ideas including its potential to improve the VR experience. The findings from this analysis are presented next.

\section{Findings}

The application of the six-step framework to the involvement of young consumers

The activities in terms of resourcing, planning and recruitment did not deviate from the original framework's recommendations (see Table 1). It was found that these steps, as conceptualized by Dietrich et al. (2017), worked well also in the context of involving young consumers as codesigners. Specifically, the three steps allowed the research team to a) prepare the co-design session including the required material and gaining support from key partners (e.g., schools), as well as to successfully recruit representatives of the respective target group. Thus, the remainder of this section focuses on the sensitization and facilitation steps of the framework. Doing so provides insights into how young consumers can be empowered to actively contribute to the design of new service ideas as experts of their experiences.

\section{Sensitizing}

The students were first introduced to the research team and the purpose of the project. This included an introduction to a simulation activity as well as the demonstration of VR equipment. In addition, students were asked to fill out a brief survey containing questions on general demographic data and their perceived peer pressure susceptibility. This enabled the research team to sort the participants into a male and female group, from which they were then randomly selected and allocated into four groups ranging from 5 to 6 members each. Each group received different sensitizing material. Table 2 provides an overview of the team compositions and the sensitizing activities completed by each group. 
Table 2 - Sensitization activities and participation levels

\begin{tabular}{|c|c|c|c|}
\hline Group Name & $\begin{array}{l}\text { Gender } \\
\text { composition }\end{array}$ & Sensitizing activity & Utility of activity \\
\hline Group 1 & $\begin{array}{l}\text { Male- only } \\
(n=6)\end{array}$ & $\begin{array}{l}\text { Roleplays: Boys were } \\
\text { instructed to re-enact first } \\
\text { scene from a male script for } \\
\text { VR house party }\end{array}$ & $\begin{array}{l}\text { To prime male participants } \\
\text { by allowing them to } \\
\text { interact with a script scene } \\
\text { first hand }\end{array}$ \\
\hline Group 2 & $\begin{array}{l}\text { Female-only } \\
(n=6)\end{array}$ & $\begin{array}{l}\text { Roleplays: Girls were } \\
\text { instructed to re-enact first } \\
\text { scene from a female script for } \\
\text { VR house party }\end{array}$ & $\begin{array}{l}\text { To prime female } \\
\text { participants by allowing } \\
\text { them to interact with a } \\
\text { script scene first hand }\end{array}$ \\
\hline Group 3 & $\begin{array}{l}\text { Mixed gender } \\
(n=5)\end{array}$ & $\begin{array}{l}\text { Video: Group viewed two } \\
\text { advertisements (male and } \\
\text { female) depicting potential } \\
\text { consequences of binge } \\
\text { drinking }\end{array}$ & $\begin{array}{l}\text { To showcase harmful } \\
\text { consequences of excessive } \\
\text { alcohol consumption for } \\
\text { young drinkers }\end{array}$ \\
\hline Group 4 & $\begin{array}{l}\text { Mixed gender } \\
(n=5)\end{array}$ & $\begin{array}{l}\text { Online simulation: Group } \\
\text { played through a simulation } \\
\text { in which they direct the } \\
\text { actions of character through a } \\
\text { night out }\end{array}$ & $\begin{array}{l}\text { To allow participants to } \\
\text { observe and direct the } \\
\text { experiences of a teenage } \\
\text { girl before and at a party } \\
\text { scenario }\end{array}$ \\
\hline
\end{tabular}

The male- and female-only group received a VR script that was customized to male and female audiences. Specifically, both groups received a pair of 'beer goggles' to simulate vision and balance impairment related to various levels of alcohol consumption. These groups were then asked to roleplay the scenes given to them by reading them out loud. The remaining two groups (both mixed-gender groups) were not given script scenes. Instead, one mixed-gender group were asked to play an interactive 'night out' simulation activity on a laptop, while the other group were invited to watch two anti-drinking advertisements developed by the Australian Government depicting various troubles a young person may encounter throughout a night resulting from excessive alcohol consumption.

Notably, different levels of participation were observed within the individual groups. These differences were categorized based on participation levels and the quantity of feedback and ideas generated (see Table 3). It was observed that the male-only and female-only groups both displayed higher levels of involvement in idea generation than the mixed-gender groups. Specifically, it was observed that the groups involved in the interactive role-playing activities (i.e., Group 1 and 2), displayed a higher level of engagement and worked more cohesively during the subsequent facilitation stage than did the groups that more passively reviewed the materials on a laptop (i.e., Group 3 and 4). The groups engaging in the roleplays started to move around, tried out the material, and enacted possible VR scenarios. This active 
involvement was subsequently maintained throughout the co-design session and also observed during the final pitch presentation.

In addition, it was observed by the research team that the students of Group 1 and 2 were more immersed in the story and could relate more closely to the characters of the VR script by enacting them. Thereby, the roleplay activities were enacted in different ways as participants swapped their roles and took on different characters. These activities exposed the groups with a variety of ideas of how such a VR script might be enacted and how its content should be designed to align with adolescent-specific preferences. In contrast, the Groups 3 and 4 could only review existing materials, thus they took on a passive outsider's perspective. These groups found it more difficult to engage in the underlying topic and collaboratively generate new ideas. Off-topic discussions and disengagement of individual group members were also repeatedly noted within both groups.

\section{Facilitation}

After the sensitization stage, all four groups were instructed to discuss and state on provided butcher papers what they liked, disliked, or wished to see added to a revised version of the script for the VR simulation experience. Hereby, tools such as butcher papers, stickers, markers, coloring pens and post-it notes were made available to each group in order to allow participants to present their ideas in a visual and creative way. One example of a butcher paper with generated ideas is presented in Figure 1.

\section{Figure 1 - Female-only team butcher paper presentation}

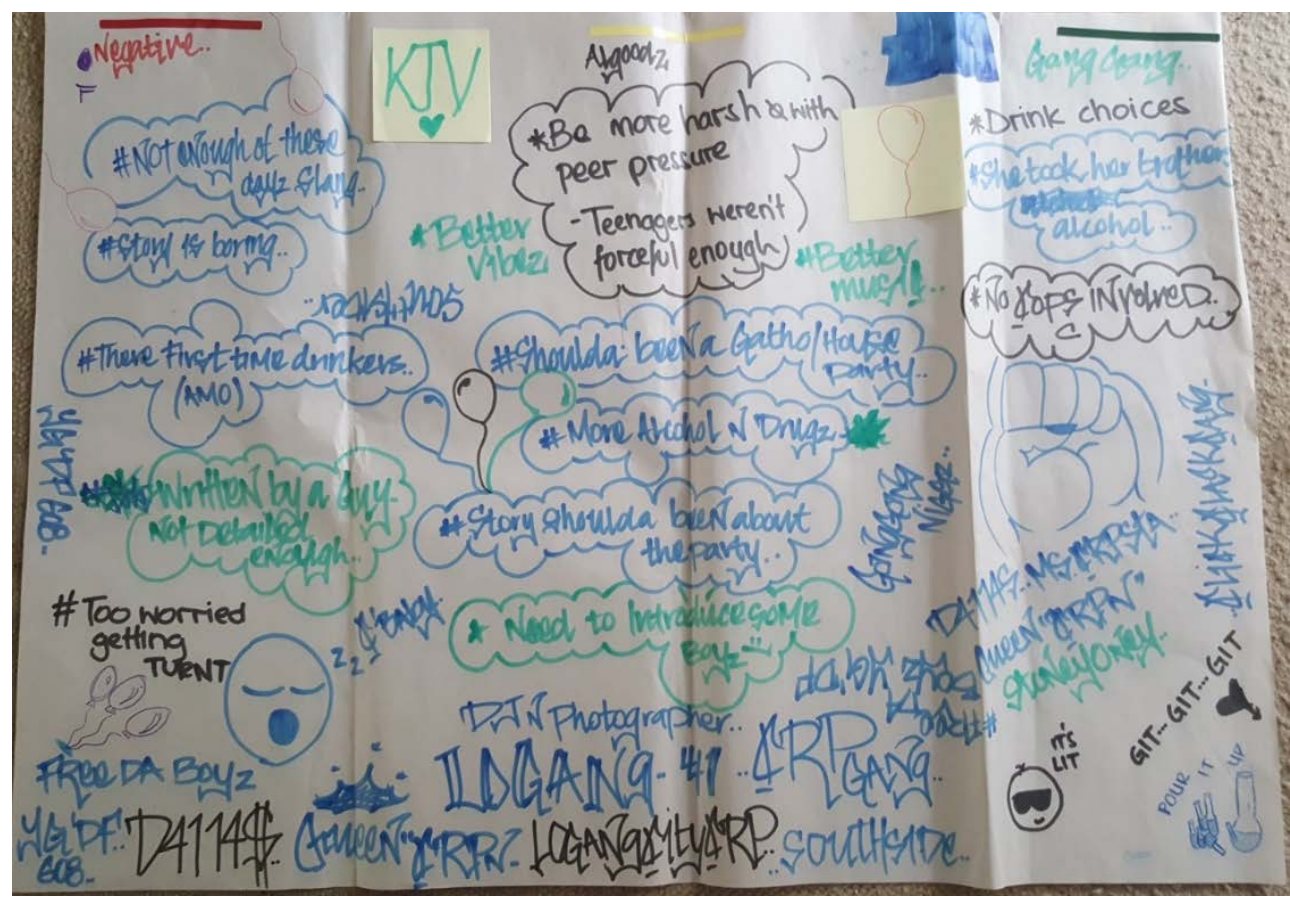


The generated ideas alongside with the pitch presentations recorded at the end of the co-design facilitation provided insights into key themes that underpin the students' inputs into the VR script. Specifically, six themes emerged from the content analysis of the butcher papers and pitch presentations across the four groups. These are, 'Party' $(\mathrm{n}=30)$, 'Characters' $(\mathrm{n}=21)$, 'Lingo' ( $\mathrm{n}=21)$, 'Context' $(\mathrm{n}=12)$, 'Realism' $(\mathrm{n}=10)$, and 'Miscellaneous' $(\mathrm{n}=16)$. Miscellaneous refers to comments that did not align with the other five reoccurring themes but were nonetheless deemed relevant by the research team.

First, participants suggested that the party scenes that were showcased within the original script scene require improvement. For instance, two groups suggested improving the look and feel of the party. They suggested including the drug use scenarios as well as put specific attention given to type of music in order to make the party more relevant to the participants' demographic:

“and people doing pills. More drug use” (Group 4 - theme: 'Party')

$$
\text { “\#better music” (Group } 2 \text { - theme: 'Party') }
$$

Second, language and characters were frequently addressed as a key part of the script design. Across the four groups it was emphasized that language and characters could be improved to more accurately represent the behavior of young consumers. Each group raised concerns that the script language and development of characters needed to be modernized, with partly very specific recommendations made by the groups:

"Make the dialogue more realistic" (Group 3 - theme: 'Realism')

"I bet ya half the class doesn't even know what introvert means..." [sic] (Group 1 - theme: 'Lingo')

"Teenagers in the script could have sworn more, as nowadays teen swear more often" (Group 4-theme: 'Lingo')

Finally, important feedback was provided in terms of how the specific context and realism of the VR script could be improved. For example, participants described that the current story was not as realistic and, at times, not entertaining enough, thus might not engage the target audience. Actionable feedback was provided by each group, which included a) better alignment of the story and contents with the realities faced by the participants, and b) higher frequency and intensity of peer pressure scenarios to make such messages clearer to the audience:

"The content \& storyline was good, but the actual information is not suitable for our generation" (Group 1 - theme: 'Context') 
“It wasn't like they had a connection with our generation so it made it very bland” (Group 1 - theme: 'Context')

“The message wasn't clear enough.” (Group 3 - theme: 'Realism')

Of central interest to the research team was the exploration of the circumstances from which the specific ideas originated from. From the observations and subsequent field notes of each research team member, specific participation roles and forms of intra-team collaboration could be identified, that were taken up by the group members. The key findings are summarized in Table 3.

Table 3 - Participation insights and group dynamics

\begin{tabular}{|c|c|c|c|}
\hline $\begin{array}{c}\text { Group name } \\
\text { and composition }\end{array}$ & Idea generation behavior & Facilitator's role & $\begin{array}{c}\text { Forms of participation and } \\
\text { engagement }\end{array}$ \\
\hline $\begin{array}{l}\text { Group } 1 \\
\text { Male-only } \\
(\mathrm{n}=6)\end{array}$ & $\begin{array}{l}\text { Highly active, with emphasis on } \\
\text { movement and working while standing. }\end{array}$ & $\begin{array}{l}\text { Facilitator provided } \\
\text { answers to task-based } \\
\text { enquiries. }\end{array}$ & $\begin{array}{l}\text { Strong intra-team collaboration } \\
\text { was evident throughout the } \\
\text { session. Two members transited } \\
\text { from being initially passive to } \\
\text { becoming more active throughout } \\
\text { the process. Strong focus on the } \\
\text { underlying task. }\end{array}$ \\
\hline $\begin{array}{l}\text { Group } 2 \\
\text { Female-only } \\
\qquad(n=6)\end{array}$ & $\begin{array}{l}\text { Unlike male counterparts, the group } \\
\text { performed roleplays while sitting } \\
\text { around a table. Extensive discussion } \\
\text { was observed from entire group, } \\
\text { mostly relevant to subject matter. }\end{array}$ & $\begin{array}{l}\text { Facilitator answered } \\
\text { queries and intervened } \\
\text { at times to get the } \\
\text { group back on track. }\end{array}$ & $\begin{array}{l}\text { Participants were initially passive } \\
\text { but after encouragement by the } \\
\text { facilitator they became more } \\
\text { actively involved and started to } \\
\text { develop the ideas collaboratively. }\end{array}$ \\
\hline $\begin{array}{l}\text { Group } 3 \\
\text { Mixed gender } \\
\quad(n=5)\end{array}$ & $\begin{array}{l}\text { Slow to start, with squabbling over } \\
\text { roles of participants (e.g., scribing } \\
\text { ideas) as well as partly on the task and } \\
\text { focus (attempted to redesign video } \\
\text { content rather than the provided VR } \\
\text { script scene). }\end{array}$ & $\begin{array}{l}\text { Facilitator had to pay } \\
\text { close attention } \\
\text { throughout to keep the } \\
\text { group focused on script } \\
\text { scene and the topic in } \\
\text { question. }\end{array}$ & $\begin{array}{l}\text { Two participants remained silent } \\
\text { at the beginning of the process, } \\
\text { but after encouragement from the } \\
\text { facilitator they became more } \\
\text { active and shared their ideas. }\end{array}$ \\
\hline $\begin{array}{l}\text { Group } 4 \\
\text { Mixed gender } \\
\quad(n=5)\end{array}$ & $\begin{array}{l}\text { Meaningful insights were made by } \\
\text { each member of the group however the } \\
\text { collaboration was interrupted by } \\
\text { numerous distractions and off-track } \\
\text { conversations. }\end{array}$ & $\begin{array}{l}\text { Facilitator intervened } \\
\text { occasionally to remind } \\
\text { participants of the task } \\
\text { in question. }\end{array}$ & $\begin{array}{l}\text { No passive participants were } \\
\text { observed, however, the forms of } \\
\text { participation changed from } \\
\text { participants partly disengaging or } \\
\text { going off-topic with their focus } \\
\text { and discussions. }\end{array}$ \\
\hline
\end{tabular}

Across the groups, different forms of participation by the individual participants and collaboration approaches were noted. Some groups contained individual participants who initially remained passive and did not contribute to the discussion (e.g., Group 3 and 4). In contrast, Group 1 and 2, showed active participation and close collaboration among all participants from the beginning of the process. On the one hand, this might have been related with the specific sensitizing approach used between the different teams. While Groups 1 and 2 engaged in activities that required them to enact a script play, Groups 3 and 4 took an observing role in reviewing videos and online simulations. On the other hand, the different forms of 
participation might be related to the specific team compositions. Notable, Group 1 and 2 contained members from the same gender, hence the groups were less diverse than Group 3 and 4. Diversity might add to the requirement of a group to bond, which requires more time, so that everyone feels comfortable to contribute actively.

In addition, some groups required close attention from the facilitators in order to ensure that they keep on track (e.g., Group 4) and to encourage all group members to contribute actively to the idea development (e.g., Group 3). Within these groups, some participants contributed partly very little throughout the process and had difficulties in keeping focused on the task or showed disinterest with the subject matter. However, other participants who initially displayed this behavior increasingly transitioned towards being more actively engaged over the course of the co-design session (e.g., members of Group 2 and 3). Hereby, the facilitator took a key position in encouraging individual participants to contribute and re-emphasizing the importance of the underlying topic to the group.

Finally, within each group a leader could be identified, which suggests that even within the short period of time the group members allocated specific roles to each other in order to address the underlying task. Those taking leadership roles were characterized by high levels of engagement and involvement, demonstrated not only from their own desire to contribute, but also in actively encouraging other group members to get involved, keeping discussions on the task, and pushing the group towards completion of the design task at hand. Other roles observed within the teams included individuals taking the responsibility in scribing, leading the discussion, and presenting the final ideas. These observations suggest that co-design is a group effort and is influenced by a) the preceding sensitizing stage, and b) the specific group composition. In addition, and specifically in the involvement of young consumers, the facilitator seems to take a key role in setting the conditions that support all participants to actively contribute their unique knowledge and experiences to a defined outcome.

\section{Discussion and Implications}

The involvement of young consumers as design partners is a challenging approach and requires careful planning to ensure success in recruitment, selection of appropriate sensitizing mechanisms as well as an evaluation to assess generated ideas. As identified by Ostrom et al. (2015) and recent studies in co-design (e.g., Dietrich et al., 2017, Trischler et al., 2017a), both scholars and practitioners lack a clear understanding on how users can be involved as active and equal contributors during the service design process. The present research goes some way 
to address this knowledge gap by investigating the involvement of young consumers in the collaborative development of a new alcohol education program component that utilizes Virtual Reality (VR). The investigation has a number of important implications for theory and practice.

This research applied the six-step co-design process as proposed by Dietrich et al. (2017). While this framework has proven to be useful for planning and facilitating co-design sessions, a number of relevant refinements are suggested to its application to contexts involving young consumers. These changes mostly concern the steps sensitization and facilitation.

First, the insights generated from this research suggest that sensitization is key to co-design projects involving young consumers. This is an important finding because other co-design studies, for example conducted in the context of lead user involvement (Trischler et al., 2017a), do not include a sensitization stage per se. By way of contrast, in the present study two stages of sensitization were utilized, one prior to, and one during the co-design session, in order to improve users understanding of the subject matter prior to idea generation. The two phases prepared the participants for the underlying design activity, as well as stimulated creativity and critical thinking. This resulted in a 'pre-sensitized' sample that came to the actual co-design session in anticipation and awareness for the subject matter. Achieving this is important because as highlighted by Iedema et al. (2010), a key challenge that is often related to co-design activities is the users' ability to interact with designers and researchers in informed discussions owing to the lacking expertise in the subject matter. As this research shows, a designated sensitization stage prior to the actual co-design can help to overcome this barrier and make young consumers into more informed participants during the co-design process.

Second, the findings show that the specific way as to how potential participants are sensitized might impact their form of participation and contribution during the actual co-design activity. Different sensitizing activities were employed in the present research. The findings revealed that for sensitizing purposes interactive methods (e.g. roleplays) appear to be more suitable than one-way communication tools (e.g. videos). The groups that used static one-way methods required much more encouragement and guidance from the facilitators throughout the codesign session. In contrast, the groups that used interactive methods demonstrated higher levels of engagement with the underlying content and completed the task more independently. These insights support previous research suggesting that methods and tools that support interactivity and hands-on activities with the underlying subject, can lead to deeper and richer data provided (Visser et al., 2005, Sanders and Stappers, 2008), as well as being more enjoyable for 
participants (Dietrich et al., 2015). Furthermore, this finding also supports the notion that different types of participation (i.e., physical, mental, and emotional participation) influences co-creation components such as value perception positively, and that the strength of each type varies contextually (Koc et al., 2017, Prebensen and Xie, 2017). This research contributes to these studies by illustrating the importance of employing such methods not only during the actual co-design activity, but also during the sensitization stage. Methods that supported playful engagement with the subject fostered active participation and user insights from multiple perspectives during the co-design session. Contrarily, static one-way sensitization activities failed to facilitate this outcome, which led to the requirement of closely guiding and encouraging participants throughout the activity. This finding points to the importance of putting specific attention on the preparation of young consumers for the co-design activity in order to enable them to become empowered and equal participants during the co-design process.

In addition, the research shows that also during the facilitation stage specific requirements need to be met in order to involve young consumers as equal 'design partners' as suggested by Druin (2002). Foremost, the provision of a trusting and open environment is key to the participants' confidence in the contributions they make. Hereby, the facilitating team emphasized that there are no wrong solutions or ideas, and rather than leading the process - an approach which is common in co-design processes (Dietrich et al., 2017), gave the teams the freedom to allocate roles and address the design task in their way. However, it is exactly the latter which sets a key challenge for co-design facilitation. On the one hand, groups might involve individual participants who dominate discussions and prevent others from sharing ideas (Trischler et al., 2017b). On the other hand, too many interferences of a facilitator might lead to a feeling of monitoring, intimidate participants, and subsequently hamper in-depth insights (Dietrich et al., 2017). This might be particularly true for co-design activities that address sensitive topics, such as in the current study. In such contexts, co-design facilitation means to find the fine line between ensuring that all participants can contribute with their unique knowledge and skills, and giving space and privacy to the groups during the process.

Finally, the findings from the present research suggest that using a team approach might be preferable over the involvement of users on an individual basis (cf. Visser et al., 2005). This is because users started to allocate specific roles and developed group dynamics that fostered creativity and insights from multiple perspectives. In fact, co-design is a team approach that uses the collective creativity from participants from diverse backgrounds and with different 
interests (Sanders and Stappers, 2008, Trischler et al., 2017a). Co-design can be approached in different ways with the facilitator either taking the role of a moderator or as a participating member of the team (Mattelmäki and Visser, 2011). The insights generated from this research however suggest, that the facilitator should not collaborate too closely with the participants. There might be a long distance between young consumers and a facilitation team consisting of design experts or researchers. This distance adds to the challenge of facilitating the process in a way so that participants do not feel constricted in their creativity and contributions. Nonetheless, co-design groups should have immediate access to facilitator when assistance is needed.

In terms of the generated outcomes, the co-design session led to a number of actionable improvements for the script design. This underlines the importance of actively involving customers and users into the service design process (Steen et al., 2011). It provides a clearer understanding of the users' value-creation processes through insights into their unique experiences and latent needs, which is key to service success (Gustafsson et al., 2012, Trischler et al., 2017a). In fact, most new services fail because they lack the ability to support customers in creating value based on the specificity of their context (Ostrom et al., 2015). This research shows that young consumers can make valuable contributions to the context-specific design of a VR content, which included here suggestions of additions, removal of components, or adjustment to the VR experience. Most suggestions concerned improvements that made the VR script more realistic to a house party involving adolescents. For example, participants made very specific suggestions to the party scene setting, the involved characters, and the language used during such a scenario. In addition, participants made changes to the dialogue in order to make the script more natural and relatable. Specifically, participants believed that the messages that intended to express peer-pressure scenarios - a key focus of the focal VR script - were not powerful enough. Their contributions led to a script that avoided overly obvious or stilted dialogues and the design of scenarios that are more aligned to the context that it sought to present.

The incorporation of these changes into the final script design might improve the identification and engagement of the respective target market with the specific activity, and the overall alcohol education program at large. On a broader scale, the VR activity might strengthen young people's resilience to peer pressure regarding alcohol consumption that is, equipping adolescents with the ability to make the right decision when it really counts. The respective VR design is currently trialed at selected high schools to determine exactly these outcomes. 


\section{Limitations and future research}

This research is not without limitations. Notable, only one session was conducted due to time and availability constraints of the participating schools. Further, the single session involved multiple activities, including a designated pre-sensitization session, which has added to the difficulty to set up additional sessions. The findings are therefore limited to one specific sample and design task. Future research is required that investigates the application of co-design with young consumers in different contexts, including users from different economic or social circumstances as well different design tasks.

In addition neither footage from, nor actual use of the VR program was utilized in the co-design session. As such, while participants were considered sufficiently sensitized towards the underlying subject (i.e., alcohol education), they were not given the opportunity to try out aspects of a VR program. This is also because VR has not yet been employed in the context of alcohol education or similar education programs. This research focused on the ideating stage during which the design typically does not have access to an existing prototype or concept (Sanders and Stappers, 2008). In fact, the use of existing designs or programs during this stage might even reduce the generated insights as participants become restricted in their thinking of what is possible and what is not (Dietrich et al., 2017). Therefore, future co-design research should move beyond the redesign of a service to innovating entirely new components. For example, rather than redesigning a provided expert script, young consumers could be invited to develop a VR plot or storyline from scratch. In the current study participants partially did this, however, insights of this kind were more framed as adjustments to current script components rather than as new plot devices. This could potentially result in new scenes or narratives to inform entirely new components of the VR experience, and as such widening the programs capabilities in catering to a larger audience of participants.

Finally, the effectiveness of the produced outcomes has not yet been evaluated. Most user involvement research focuses on identifying radical new ideas that are valuable for the firm's innovation process (Witell et al., 2011, Trischler et al., 2017a). Co-design processes involving topics as investigated here are likely to follow different outcome objectives, such as transformation and improving consumer well-being. However, a framework that enables a systematic evaluation of well-being dimensions is lacking, and has therefore been defined as an important research priority (Ostrom et al., 2015). In the current study, participants contributed unique knowledge about their needs and preferences. Their contributions informed 
the VR design and were balanced against feasibility which was considered by the service design team in terms of cost and time to market. Nonetheless, a key area for future research is the evaluation of the value of co-design using a large-scale empirical study. 


\section{Reference List}

ALHABASH, S., MCALISTER, A., QUILLIAM, T., RICHARDS, J. \& LOU, C. 2015. Alcohol's Getting a Bit More Social: When Alcohol Marketing Messages on Facebook Increase Young Adults' Intentions to Imbibe. Mass Communication and Society, 18, 350-375.

BAKER, S. M., GENTRY, J. W. \& RITTENBURG, T. L. 2005. Building understanding of the domain of consumer vulnerability. Journal of Macromarketing, 25, 128139.

BARKO, T. \& SADLER, T. D. 2012. Practicality in Virtuality: Finding Student Meaning in Video Game Education. Journal of Science Education and Technology, 22, 124-132.

CHAPLIN, L. N., HILL, R. P. \& JOHN, D. R. 2014. Poverty and Materialism: A Look at Impoverished Versus Affluent Children. Journal of Public Policy \& Marketing, 33, 78-92.

DETERDING, S., DIXON, D., KHALED, R. \& NACKE, L. From game design elements to gamefulness: Defining gamification. 15th International Academic MindTrek Conference, September 28-30, 20112011 Tampere, Finland.: ACM, 9-15.

DIETRICH, T., RUNDLE-THIELE, S., LEO, C. \& CONNOR, J. P. 2015. One size (never) fits all: segment differences observed following a school-based alcohol social marketing program. J Sch Health, 85, 251-9.

DIETRICH, T., RUNDLE-THIELE, S., SCHUSTER, L. \& CONNOR, J. P. 2016. Codesigning social marketing programs. Journal of Social Marketing, 6, 41-61.

DIETRICH, T., TRISCHLER, J., SCHUSTER, L. \& RUNDLE-THIELE, S. 2017. Codesigning services with vulnerable consumers. Journal of Service Theory and Practice, 27, 663-688.

DRUIN, A. 2002. The role of children in the design of new technology. Behaviour \& Information Technology, 21, 1-25.

EDVARDSSON, B., GUSTAFSSON, A. \& ROOS, I. 2005. Service portraits in service research: a critical review. International Journal of Service Industry Management, 16, 107-121.

ELG, M., ENGSTRÖM, J., WITELL, L. \& POKSINSKA, B. 2012. Co-creation and learning in health-care service development. Journal of Service Management, 23, 328-343.

ENGSTRÖM, J. \& ELG, M. 2015. A self-determination theory perspective on customer participation in service development. Journal of Services Marketing, 29 511521.

FOXCROFT, D. R. \& TSERTSVADZE, A. 2011. Universal school-based prevention programs for alcohol misuse in young people. Cochrane Database Syst Rev, CD009113.

GUSTAFSSON, A., KRISTENSSON, P. \& WITELL, L. 2012. Customer co-creation in service innovation: A matter of communication? Journal of Service Management, 23 311-327.

HAMARI, J., KOIVISTO, J., SARSA, H. Does Gamification Work? - A Literature Review of Empirical Studies on gamification. 47th Hawaii International Conference on System Sciences, January 6-9, 20142014 Hawaii, USA.

HOCUTT, M. A. \& STONE, T. H. 1998. The impact of employee empowerment on the quality of service recovery effort. Journal of Quality Management, 3, 117. 
HOLMLID, S. 2009. Participative, Co-Operative, Emancipatory: From Participatory Design to Service Design. First Nordic Conference on Service Design and Service Innovation. Oslo.

IEDEMA, R., OSWICK, C., GRANT, D., MARSHAK, R. J., WOLFRAM-COX, J., MERRICK, E., PIPER, D., BRITTON, K., GRAY, J., VERMA, R. \& MANNING, N. 2010. Codesigning as a Discursive Practice in Emergency Health Services: The Architecture of Deliberation. The Journal of Applied Behavioral Science, 46, 73-91.

IND, N. \& COATES, N. 2013. The meanings of co-creation. European Business Review, 25, 86-95.

IWAMOTO, D. K. \& SMILER, A. P. 2013. Alcohol makes you macho and helps you make friends: the role of masculine norms and peer pressure in adolescent boys' and girls' alcohol use. Subst Use Misuse, 48, 371-8.

JONES, S. C., ANDREWS, K. \& FRANCIS, K. 2017. Combining Social Norms and Social Marketing to Address Underage Drinking: Development and Process Evaluation of a Whole-of-Community Intervention. PLoS One, 12, e0169872.

KOC, E., ULUKOY, M., KILIC, R., YUMUSAK, S. \& BAHAR, R. 2017. The influence of customer participation on service failure perceptions. Total Quality Management \& Business Excellence, 28, 390-404.

KRIPPENDORFF, K. 2006. The Semantic Turn: A new Foundation for Design, Boca Raton, Taylor \& Francis.

LEE, N. K., CAMERON, J., BATTAMS, S. \& ROCHE, A. 2016. What works in schoolbased alcohol education: A systematic review. Health Education Journal, 75, 780-798.

LEHRER, M., ORDANINI, A., DEFILLIPPI, R. \& MIOZZO, M. 2012. Challenging the orthodoxy of value co-creation theory: A contingent view of co-production in design-intensive business services. European Management Journal, 30, 499509.

LEONTINI, R., SCHOFIELD, T., BROWN, R. \& HEPWORTH, J. 2016. "Drinking Cultures" in University Residential Colleges. Contemporary Drug Problems, 44, 32-48.

MATTELMÄKI, T. \& VISSER, S. F. Lost in Co-X: Interpretations of Co-design and Cocreation. International Association of Societies of Design Research 2011: Diversity and Unity, 31 October - 4 November 20112011 Delft, The Netherlands.

NEWTON, N. C., CONROD, P. J., SLADE, T., CARRAGHER, N., CHAMPION, K. E., BARRETT, E. L., KELLY, E. V., NAIR, N. K., STAPINSKI, L. \& TEESSON, M. 2016. The long-term effectiveness of a selective, personality-targeted prevention program in reducing alcohol use and related harms: a cluster randomized controlled trial. J Child Psychol Psychiatry, 57, 1056-65.

ONRUST, S. A., OTTEN, R., LAMMERS, J. \& SMIT, F. 2016. School-based programmes to reduce and prevent substance use in different age groups: What works for whom? Systematic review and meta-regression analysis. CLINICAL PSYCHOLOGY REVIEW, 44, 45-59.

OSTROM, A. L., PARASURAMAN, A., BOWEN, D. E., PATRÍCIO, L. \& VOSS, C. A. 2015. Service Research Priorities in a Rapidly Changing Context. Journal of Service Research, 18, 127-159.

PATRÍCIO, L. \& FISK, R. 2013. Creating New Services. Serving Customers: Global Services Marketing Perspectives. Tilde University Press. 
PATRÍCIO, L., FISK, R., FALCÃO E CUNHA, J. \& CONSTANTINE, L. 2011. Multilevel service design: From customer value constellation to service experience blueprinting. Journal of Service Research, 14 180-200.

PERRY, C. \& GUMMESSON, E. 2004. Action research in marketing. European Journal of Marketing, 38 310-320.

PREBENSEN, N. K. \& XIE, J. H. 2017. Efficacy of co-creation and mastering on perceived value and satisfaction in tourists' consumption. Tourism Management, 60, 166-176.

ROCHE, A. M., BYWOOD, P., HUGHES, C., FREEMAN, T., DURAISINGAM, V., TRIFONOFF, A., TOVELL, A. \& STEENSON, T. 2010. The Role of Schools in Alcohol Education: Final Report. Adelaide, SA: Flinders University.

SALOM, C. L., KELLY, A. B., ALATI, R., WILLIAMS, G. M., PATTON, G. C. \& WILLIAMS, J. W. 2016. Individual, school-related and family characteristics distinguish co-occurrence of drinking and depressive symptoms in very young adolescents. Drug Alcohol Rev, 35, 387-96.

SANDERS, E. B. N. \& STAPPERS, P. J. 2008. Co-creation and the new landscapes of design. CoDesign, 4, 5-18.

STEEN, M., MANSCHOT, M. A. J. \& DE KONING, N. 2011. Benefits of co-design in service design projects. International Journal of Design, 5, 53-60.

THURMAN, B., \& BOUGHELAF, J. 2015. We don't get taught enough.' An assessment of drug education provision in schools in England. . Drugs \& Alcohol Today, 15.

TOUMBOUROU, J. W., GREGG, M. E., SHORTT, A. L., HUTCHINSON, D. M. \& SLAVIERO, T. M. 2013. Reduction of adolescent alcohol use through familyschool intervention: a randomized trial. J Adolesc Health, 53, 778-84.

TRISCHLER, J., PERVAN, S. J., KELLY, S. J. \& SCOTT, D. R. 2017a. The value of codesign: The effect of customer involvement in service design teams. Journal of Service Research, OnlineFirst, 1-26.

TRISCHLER, J., PERVAN, S. J. \& SCOTT, D. R. 2017b. Exploring the "black box" of customer co-creation processes. Journal of Services Marketing, 31, 265-280.

TUPPER, K. W. 2008. Teaching teachers to just say "know": Reflections on drug education. Teaching and Teacher Education, 24, 356-367.

VAAJAKALLIO, K., LEE, J. J., AND MATTELMÄKI, T. It has to be a group work!: codesign with children. . 8th International Conference on Interaction Design and Children, 2009. ACM, 246-249.

VAN MECHELEN, M., ZAMAN, B., VANDEN ABEELE, V. \& LAENEN, A. 2013. Codesign revisited: exploring problematic co-design dynamics in kids. CHI 2013 workshop: Methods of Working with Teenagers in Interaction Design. Paris, France: ACM.

VARGO, S. L. \& LUSCH, R. F. 2008. Service-dominant logic: Continuing the evolution. Journal of the Academy of Marketing Science, 36 1-10.

VERGANTI, R. 2008. Design, meanings, and radical innovation: A metamodel and a research agenda. Journal of Product Innovation Management, 25, 436-456.

VISSER, F. S., STAPPERS, P. J., VAN DER LUGT, R. \& SANDERS, E. B. N. 2005. Contextmapping: experiences from practice. CoDesign, 1, 119-149.

WETTER-EDMAN, K., SANGIORGI, D., EDVARDSSON, B., HOLMLID, S., GRÖNROOS, C. \& MATTELMÄKI, T. 2014. Design for Value Co-Creation: Exploring Synergies Between Design for Service and Service Logics. Journal of Service Science, 6.

WHO 2014. Global status report on alcohol and health, World Health Organisation. 
WITELL, L., KRISTENSSON, P., GUSTAFSSON, A. \& LÖFGREN, M. 2011. Idea generation: customer co-creation versus traditional market research techniques. Journal of Service Management, 22, 140-159.

YIN, R. 2011. Qualitative Research from Start to Finish, New York., The Guilford Press,. 